\title{
Potencialidades do filme de ficção Avatar para a alfabetização científica dos sujeitos no contexto da educação básica
}

\author{
Potentialities of the fiction movie Avatar for the scientific literacy of \\ subjects in the context of basic education
}

\author{
Wagner José dos Santos ${ }^{1}$ \\ Ivanderson Pereira da Silva ${ }^{2}$
}

\section{Resumo}

Este estudo investigou as potencialidades do filme de ficção Avatar para o desenvolvimento de currículos cujo fio condutor é a abordagem Ciência, Tecnologia, Sociedade e Ambiente (CTSA) e que estão voltados para a alfabetização científica dos sujeitos no contexto da educação básica. Para isso, foram explorados os recursos metodológicos da etnografia de tela para explorar cenários problematizadores que favoreçam o processo de alfabetização científica dos sujeitos a partir do filme de ficção científica Avatar. Como resultados desse movimento de pesquisa, observamos que a partir de um trabalho voltado para a construção de currículos CTSA é possível problematizar através nas cenas do filme de ficção Avatar, questões relacionadas à origem da vida; sustentabilidade; fenômenos físicos como gravitação e magnetismo; a fauna e a flora; teoria da evolução das espécies; aspectos culturais, éticos e religiosos emergentes e necessários para o processo de alfabetização científica dos sujeitos. Além disso, o apelo visual do filme associado ao enredo envolvente pode contribuir para despertar nos alunos o interesse pela ciência, não só na área da biologia, mas também na sociologia, filosofia, ensino religioso, geografia, física e química. Os apontamentos feitos no trabalho demonstraram que o filme pode ajudar no desenvolvimento de um trabalho pedagógico nas diferentes áreas do conhecimento ou em projetos interdisciplinares.

Palavras chave: Avatar; cinema; alfabetização científica.

\section{Abstract}

This paper has investigated the potential of the fiction movie Avatar for the development of curricula whose guiding principle is the Science, Technology, Society and Environment (CTSA) approach and which are focused on the scientific literacy of subjects in the context of basic education. For this, the methodological resources of screen ethnography were explored to explore problematizing scenarios that favor the scientific literacy process of the subjects from the science fiction movie Avatar. As results of this research movement, we observe that from a work aimed at the construction of CTSA curricula it is possible to problematize through the scenes of the Avatar movie, questions related to the origin of life;

\footnotetext{
${ }^{1}$ Universidade Federal de Alagoas | wjs.wagner13@gmail.com

${ }^{2}$ Universidade Federal de Alagoas | ivanderson@gmail.com
} 
sustainability; physical phenomena such as gravitation and magnetism; fauna and flora; theory of species evolution; cultural, ethical and religious aspects that are necessary and necessary for the scientific literacy process of the subjects. In addition, the visual appeal of the movie associated with the surrounding storyline can help awaken interest in science, not only in biology, but also in sociology, philosophy, religious education, geography, physics, and chemistry. The notes made in the work demonstrated that the movie can help in the development of a pedagogical work in the different areas of knowledge or in interdisciplinary projects.

Keywords: Avatar; movie; scientific literacy

\section{Introdução}

O uso de filmes de ficção científica numa abordagem Ciência, Tecnologia, Sociedade e Ambiente (CSTA) pode se constituir num recurso que favoreça a alfabetização científica dos sujeitos (EGGENSPERGER, 2009; RINK, 2010; RESENDE, 2010). Dentro dessa perspectiva, "O estudo de temas em currículos CTS [CTSA] permite a introdução de problemas sociais, cujas possíveis soluções são propostas em sala de aula a partir do estudo de conteúdo científico, suas aplicações tecnológicas e consequências sociais" (SILVA; MORTIMER, 2012, p. 242). A exemplo desse tipo de cenário é possível apontar as experiências de Eggensperger (2009), Rink (2010) e Resende (2010) com o uso do filme de ficção científica Avatar (BAXTER, 2013).

O filme de ficção Avatarjá foi utilizado em outros contextos educacionais, como por exemplo: para discussão entre diferenças culturais e étnicas, por Eggensperger (2009); problematizar questões relacionadas a valores sociais e antropológicos, por Rink (2010); para exploração de conceitos relacionados a educação ambiental, por Resende (2010). Dadas as suas possibilidades didáticas, é possível sugerir que esse possa se constituir num veículo facilitador da alfabetização científica dos sujeitos.

Chassot (2003, p.9) destaca a necessidade da alfabetização científica dos sujeitos no cenário contemporâneo. Uma abordagem preocupada com a alfabetização científica dos sujeitos precisa partir de uma perspectiva problematizadora, já que problematizar é tornar o estudante capaz de criar, pensar, explorar todo e qualquer tipo de conhecimento, sempre na busca por uma solução do problema investigado (MACHADO; SASSERON, 2012).

Nesse sentido, emergiu o seguinte problema de pesquisa: Quais as potencialidades do filme de ficção Avatar para desenvolvimento da alfabetização científica dos sujeitos no contexto da educação básica?

O trabalho analisou o filme Avatarno sentido de explorar suas potencialidades para a construção de um currículo CTSA voltado para a alfabetização científica dos sujeitos. Para isso, foram explorados os recursos metodológicos da etnografia de tela que consiste numa abordagem interdisciplinar, que une a análise do audiovisual (que combina conhecimentos sobre imagem, cinema, linguagem audiovisual, semiótica e sintaxe) com a teoria e a metodologia antropológica (BALESTRIN; SOARES, 2012) .

A etnografia de tela compreende tanto a aplicação de procedimentos da pesquisa etnográfica (observação e registro em diário de campo), como instrumentos da análise filmica: movimentos de câmera, planos, construção de cenários, personagens, diálogos, elementos estéticos como a luz e a cor entre outras (BALESTRIN; SOARES, 2012). De acordo com Rial (1995) as produções midiáticas não são neutras, elas apresentam uma realidade, mas também a instituem e problematizam. Daí a importância das imagens e os sons 
registrados, a forma como são organizados, seus conteúdos e formas de divulgação. Ainda de acordo com Rial (1995)

A etnografia do filme Avatar foi realizada, buscando elementos em seu enredo que contribuam para a construção de cenários problematizadores em sala de aula e com isso favoreçam o processo de alfabetização científica dos sujeitos. Assim, nesse estudo, abordaremos, num primeiro momento, os conceitos de alfabetização científica e por fim, apresentaremos os resultados do movimento de etnografia de tela do filme Avatar com foco em suas potencialidades didáticas.

\section{Alfabetização científica}

A sociedade contemporânea vive em um mundo influenciado pela ciência e a tecnologia. A partir de um olhar em perspectiva, observamos que os avanços científicos e tecnológicos revelam um grande salto da humanidade em termos de construção do conhecimento, nas mais variadas áreas. A televisão, o rádio, o computador e a internet diminuíram o tempo com que as informações são transmitidas, chegando a uma velocidade nunca vista antes.

Segundo Sasseron (2015) é evidente a influência da ciência promoveu mudanças e avanços na paisagem natural e na vida em sociedade. Deste modo, conhecer como a ciência está em constante transformação, é fundamental para entender esses avanços científicos e como pode promover impactos em nossa vida.

Chassot (2003) destaca que não é raro, existirem alunos que superam professores e professoras em acesso a fonte de informações, conectados em redes de TV a cabo ou navegado na internet. Sendo assim, a escola não pode ser um local de simples transmissão de conhecimento. Ensinar nesse contexto de aceleradas transformações, exige um currículo flexível e metodologias de ensino mais abertas a pesquisa e à comunicação (MORAN, 2008).

Conforme ressalta Bizzo (2002) o ensino de ciências não deve mais se restringir a transmitir conhecimento de forma mecânica, sem considerar o conhecimento prévio dos protagonistas do processo de aprendizagem. Ao contrário, deve se voltar para a promoção e o desenvolvimento de habilidades que despertem um incômodo epistemológico (FREIRE, 1996) diante do desconhecido, buscando explicações para os fenômenos vistos em sala de aula e para além dela.

Muitas discussões surgiram para propor formas de o estudante contemporâneo compreender e interferir na ciência e na tecnologia através dos processos educativos. Dessas discussões, surgiu o conceito de alfabetização científica, que busca um novo rumo para o ensino de ciência (CAJAS, 2001). Com isso, o ensino de ciências tradicional, em que o estudante era apenas receptor de conhecimento, passa a ser trabalhado, levando em consideração a sua utilidade.

Para Lacerda (1997) a Alfabetização Científica é a aquisição dos princípios científicos de base para compreender, interpretar e interferir em discussões relacionadas ao uso da ciência e da tecnologia. Já Sasseron e Carvalho (2011a) a definem como uma sequência de ações que incentivem os estudantes a buscarem uma nova forma de perceberem os acontecimentos do mundo.

Ao estudar a literatura estrangeira relacionada ao ensino de Ciências, percebe-se uma variação no uso do termo Alfabetização Científica, sendo definida como: Alfabetización Científica (no idioma espanhol), Scientific Literacy (no idioma inglês), Alphabétisation 
Scientifique (no idioma francês) e mesmo no Brasil se percebe o uso dos termos Letramento Científico, Enculturação Científica, Alfabetização Científica ou ainda Alfabetização Científica e Tecnológica, para definir essa preocupação com a formação de um sujeito que possa compreender esse cenário contemporâneo altamente permeado e influenciado pela ciência e seus produtos, e consequentemente possa nele intervir(SASSERON; CARVALHO, 2011b).

Segundo Auler (2003) o ensino de ciências com um enfoque na alfabetização científica e tecnológica pode promover um melhor aproveitamento escolar, pois permite a aquisição de habilidades e competências para atuar de forma mais crítica. Sendo assim, o ensino formará cidadãos que consigam aplicar o conhecimento em situações cotidianas como no funcionamento de um chuveiro elétrico. Caramello et al. (2010, p. 4) apontam nove aspectos que contribuem para a promoção da alfabetização científica e tecnológica:

Natureza da ciência, natureza da tecnologia, natureza da sociedade, efeitos da ciência sobre a tecnologia, efeitos da tecnologia sobre a sociedade, efeitos da sociedade sobre a ciência, efeito da ciência sobre a sociedade, efeito da sociedade sobre a tecnologia, efeito da tecnologia sobre a ciência.

Sendo assim, um professor ao levar um tema para a sala de aula não deve esquecer as relações entre CTSA, pois tais conceitos são ferramentas-chave para a construção de um aluno alfabetizado em ciência e tecnologia. A abordagem CTSA persegue uma educação científica e ambiental na promoção de uma pensamento crítico e consciente dos estudantes sobre vários aspectos presentes no mundo (FAVILA; ADAIME, 2013). O conceito de tecnologia pode ser entendido de várias maneiras, para Maia (2000) ele é uma aplicação da ciência; já Demo (2002) entende que a tecnologia é a construção do espírito humano; Silva e Silva (2008) afirmam que ela é a ferramenta usada para entender as habilidades que podemos desenvolver. Nesse sentido, consideramos que o filme de ficção Avatar apresente alto potencial didático para o desenvolvimento de currículos CTSA voltados para a alfabetização científica dos sujeitos.

\section{As potencialidades didáticas do filme de ficção avatar}

Avatar é um filme do gênero ficção escrito e dirigido por James Cameron, produzido em 2009 por Lightstorm Entertainment e 20thCentury Fox. O filme instiga de forma singular a imaginação de todos que o assistem e sua tecnologia promove uma experiência sensorial ímpar. A exemplo disso, é possível descrever a sala de controle de Centro de Operações que é equipada comwraparoud, ou seja, controles curvos e panorâmicos que respondem ao toque e uma mesa holográfica com uma visão detalhada de toda área de atividade. Em outra cena, no laboratório de avatares, o Dr. Max Patel (cientista do Programa Avatar) passa as imagens de um tablet para o outro, como se tirasse de um pedaço de papel de um quadro de avisos. Também se observam vários displays tridimensionais em todo o laboratório.

O filme Avatar foi o primeiro o filme que consagrou a tecnologia 3D (três dimensões) no cinema. A descrição das potencialidades do filme Avatar para a construção de currículos CTSA voltados para a alfabetização científica dos sujeitos foram categorizadas a partir de sua etnografia de tela (RIAL, 1995) e estão descritas a seguir: 


\section{a) Origem da vida}

A história se passa no futuro, século 22, em Pandora, uma lua do Planeta Polyphemus situada no sistema Alfa Centauri A, a aproximadamente 4,4 milhões de anos-luz da Terra. Os humanos chegaram a Pandora através do veículo interestelar chamado Venture Star, um cargueiro interestelar com uma rota regular entre a Terra e Pandora.

Um ponto já relevante do filme seria a análise da possibilidade da existência de vida em uma lua e a reflexão sobre as condições são favoráveis para o surgimento dela. Sobre a temática pode-se explorar as ideias presentes na Astrobiologia, na qual visa à compreensão da origem e evolução da vida no universo (RODRIGUES, et al., 2016). O professor poderia inserir essa temática trazendo uma proposta desse conhecimento e procurando formular hipóteses acerca da possibilidade da existência de vida além dos limites da Terra. Questões como: estamos sós no universo? Qual o futuro da vida na Terra e no universo? Como a vida se originou?

Poder-se-ia ter uma ideia melhor da probabilidade de um mundo como Pandora abrigar vida, se tivéssemos uma ideia clara de como a vida iniciou a vida na Terra. Com o filme Avatarse poderia explorar junto aos estudantes a ideia de panspermia, o surgimento de vida a partir de outros lugares do universo. Uma hipótese recente sobre a panspermia foi desenvolvida por Hoyle e Wikramasinghe (2000). Esses autores defendem que a ideia de seres que existem fora Terra não é surreal. Alguns vírus poderiam chegar a Terra quase todo dia, trazidos por cometas. É uma temática que pode gerar várias questões que poder ser discutidas pelos alunos e pelos professores durante as aulas de ciências ou para além delas.

\section{b) Sustentabilidade}

Em Pandora por volta do ano 2154 uma empresa corporativa conhecida como Resources Development Administration(RDA), Administração de Desenvolvimento de Recursos, é responsável por explorar os recursos naturais presentes no lugar. A RDA é considerada a maior organização não governamental na Terra e no Universo Humano, possuindo o monopólio de todos os produtos enviados, derivados ou desenvolvidos em Pandora ou em qualquer local fora da Terra.

O principal recurso explorado em Pandora é um mineral chamado de Unobtanium, material supercondutor de alta temperatura, valiosíssimo e útil nas mais diversas aplicações tecnológicas. Sua descoberta ocorreu através de explorações por riquezas minerais em outros lugares do universo. As poucas cenas da Terra vistas no filme Avatar mostram um planeta em colapso, no qual os recursos naturais até então presentes se esgotaram. Desta forma, surgem perguntas iniciais que poderiam problematizar uma aula. Como por exemplo: seria possível o esgotamento dos recursos do planeta Terra? A humanidade poderia viver assim? De onde vêm os recursos minerais para a produção de equipamentos tecnológicos como celulares, tablets e computadores? O professor poderia criar uma aula na qual os alunos realizariam pesquisas sobre as questões levantadas anteriormente. Poderiam realizar um debate mediado pelo professor sobre a temática. Vale ressaltar que alguns dos equipamentos tecnológicos fazem parte da vida cotidiana dos alunos, como celulares e computadores, porém, os mesmos, desconhecem a importância de alguns minerais como o silício na fabricação desses equipamentos. 
Na medida em que enfrentam uma escassez de recursos que são fundamentais para a sobrevivência dos seres vivos, não seria difícil imaginar o futuro que surgirá, como guerras, fome, doenças, migrações em massa, catástrofes naturais, enchentes, furacões, processo de aquecimento entre outros.

As mudanças que estão sofrendo o planeta estão ocorrendo de forma gradual e as pequenas mudanças, à luz da reflexão favorecida pelo filme, poderão se tornar grandes catástrofes de valor irreparável. O filme tem essa temática apresentado de forma bastante significativa, usá-lo para despertar o interessante do aluno por questões ambientais pode ser bastante interessante.

Lovelock (2000) em sua teoria conhecida como Hipótese Gaiaconsidera o planeta um grande organismo, com um sistema fisiológico dinâmico e que promove o equilíbrio do planeta a mais de 3 bilhões de anos. Talvez Gaia tenha um paralelo com Eywa, presente no filme Avatar, responsável pelo equilíbrio biológico de Pandora. O autor ainda afirma que o planeta está reagindo, dos bilhões de humanos que existem atualmente no planeta, poucos sobreviverão, mas o planeta conseguirá ser reerguer e promover o equilíbrio novamente.

No filme Avatar se observa um comportamento de preservação adotado pelo povo Na'vi (povo habitante de Pandora), a cobiça dos humanos pela exploração das riquezas minerais e a busca de "lucro por lucro" sem considerar um possível esgotamento desses recurso. Tudo isso nos permite uma reflexão sobre a relação do homem com natureza, assim como a conduta pessoal de cada um diante de questões ambientais. Isso permite aos sujeitos uma nova maneira de pensar sobre os seres que compõem o mundo, assim como plantas, animais e humanos. O filme exemplifica muito bem esse conflito entre economia $x$ natureza, além de favorecer discussões acerca de uma necessária mudança de postura diante dos problemas ambientais presentes em nosso planeta.

De acordo com Wapner (1996) ambientalista norte-americano, as linhas divisórias entre a natureza e os seres humanos devem ser brandas, evitando um colapso dos recursos disponíveis no meio ambiente. Porém o que se nota é uma constante exploração desses recursos naturais e um extrativismo exagerado, provocando grande degradação da natureza, além de grande dificuldade em preservar áreas de elevada riqueza de recursos naturais. Sendo assim, os alunos poderiam pesquisar sobre empresas brasileiras atuam com um viés sustentável e poderiam apresentar para os colegas de sala, destacando como a atitude dessas empresas ajudam na redução dos impactos causados no meio ambiente.

\section{c) Fenômenos físicos}

Em uma das cenas o Coronel Quaritch, chefe da segurança, chama Jake para uma conversa particular e quanto esse chega ao local combinado eles está realizando um exercício de musculação, supino reto. Coronel comenta, que a gravidade baixa de Pandora "vai deixar você mole, e se ficar mole Pandora acaba com você sem nenhum aviso" (AVATAR, 2009).

As condições atmosférias de Pandora são bem diferentes do ambiente terrestre. A gravidade é menor, o ar é mais denso e sem oxigênio, possui forte campo magnético em todo lugar. Desta forma, os corpos dos seres de Pandorapodem ter sido produtos de um processo evolutivo que se deu ao longo do tempo (DARWIN, 2004). É nessa linha que o ensino pode ser bastante interessante para o aluno, visto que, entender como cada um desses fatores ambientais, como gravidade, o ar, campo magnético influenciam na 
característica de cada ser presente em um ambiente pode despertar o interesse dos estudantes.

Outro ponto de destaque que podem contribuir para o ensino de conceitos físicos presentes em Avatar,é que a temática sobre o campo magnético que tem como causa o mineral Unobtabium, apresentado no filme como um supercondutor, capaz de produzir um forte campo magnético com capacidade de erguer montanhas.

Uma atividade prática sobre magnetismo em sala de aula com pequenos ímãs poderia ser uma alternativa interessante de trabalho sobre a temática, apresentado aspectos do material para os alunos, como campo magnético, pressão magnética, densidade de energia entre outros. Além de promover alguns questionamentos como, por exemplo, se seria capaz de surgir montanhas flutuantes na Terra como as vistas em Pandora.

Um dos cenários mais espetaculares de Pandora são as montanhas flutuantes ou "Montanhas Aleluia", são montanhas gigantescas que se movem lentamente, semelhantes a icebergs no oceano. O fenômeno só é possível com a ajuda do Unobtanium. É da interação da substância com o campo magnético local que vem a força capaz manter flutuando as gigantescas montanhas. Usando esse cenário o professor poderia questionar quão forte deveria ser um campo magnético para erguer uma montanha? Essa seria uma questão bastante interessante para resolvê-la através de cálculos matemáticos. Também seria possível usar ímã para uma aula prática com esse enfoque na força de atração e repulsão.

Outro ponto para ser abordado com a temática do magnetismo seria a sua influência em animais da Terra, visto que, alguns animais dispõem de uma bússola magnética interna, e se orientam a partir da direção dos polos do campo magnético. Esse fenômeno é chamado de magnetorrecepção (WALKER; GREEN, 2000). É comum em animais como tartarugas, aves, morcegos, lagostas e salamandras.

\section{d) Fauna e Flora}

Em uma das cenas Jake, em corpo avatar, está fugindo de um Thatator (Thanatora ferox), considerado o maior predador terrestre de Pandora, tem hábito alimentar onívoro e se apresenta como uma criatura de seis patas, com placas de exoesqueleto no pescoço e duas antenas. O filme Avatar apresenta seres com características tão peculiares e diversas. Levar essa abordagem para a sala aula seria uma estratégia bastante interessante para os alunos.

$\mathrm{Na}$ análise dos seres vivos de Pandora percebe-se muitas semelhanças com os seres que vivem na Terra, como por exemplo a vida multicelular e complexa dos vários organismos existente. A fauna do lugar (Pandora) é composta por muitos vertebrados, de esqueleto interno, assim como o grupo de vertebrados terrestres.

Mesmo com essas semelhanças entre os seres da Terra e de Pandora, nota-se também algumas diferenças. Os animais vistos nas florestas de Pandora geralmente possuem seis membros. Isso pode ser explorado pelos professores através de uma análise comparativa da morfologia e fisiologia dos seres de Pandora e da Terra. Os alunos identificarão como indivíduos conseguiram se adaptar aos ambientes que habitam.

Os animais de Pandora geralmente são grandes, mesmo o Direhorse (Equidirus hoplites) (animal semelhante a um cavalo) é maior que qualquer cavalo da Terra. O animal mais pesado vivente na Terra é o elefante africano (Loxodonta), um macho pode atingir até quatro metros de altura. Em Pandora, o maior animal terrestre é o Titanotério cabeça de martelo (Titanotheris hammercephalis), com aproximadamente seis metros de altura. 
É possível problematizar junto aos alunos se a gravidade reduzida de Pandora influenciou as formas de vida gigantes das criaturas de Pandora. Sobre o número de patas, grande parte dos animais de Pandora possuem seis membros, mas será que também é para suportar o elevado peso? É possível problematizar essa questão junto aos alunos à luz dos exemplos terrestes. Em nosso caso, os hexapoditos (animais de seis patas) presentes na Terra são os insetos, que estão entre os menores seres com patas, também existiam os dinossauros que eram as maiores criaturas da Terra e possuíam quatro membros.

São problemas a partir dos quais o professor poderia criar uma discussão pertinente sobre esses pontos de vista ou até outros que possam ser levantados pelos alunos. Explorar as características das criaturas de Pandora, como sua morfologia e fisiologia, sua etologia e análise de nichos ecológicos, são momentos que podem enriquecer uma aula de biologia.

No que concerne à flora, em uma das cenas, Jake em seu corpo avatar, se encontra na floresta e percebe pela primeira vez a abundância de vida emPandora. Jake fica encantado com plantas gigantes em forma de espiral com a aparência de um trompete (Helicoradium spirale) que encolhem ao solo quando tocadas. Jake fica deslumbrado com as gigantescas árvores e com toda a diversidade da flora presente no local.

O professor poderia usar esse trecho e outros semelhantes do filme para uma aula de botânica (estudo dos vegetais). Apresentando as relações entre as árvores de Pandora e da Terra. Poderia abordar, por exemplo, o transporte de seiva pelos vegetais, no qual na Terra a altura das árvores é uma característica fundamental para a sua sobrevivência, pois quanto maior a árvore maior a pressão exercida pelos vasos para fazer subir a seiva até a folha e realizar a fotossíntese.

A árvore mais alta da Terra é a Sequoia (Sequoidendron gigantea), podendo atingir até 116 metros de altura. Já a Árvore-Lar do povo Omatycaia de Pandora tem cerca de 300 metros de altura, quase três vezes o tamanho da maior árvore terrestre.Diante dessa informação poderia ser iniciada uma atividade investigativa, no qual os alunos buscariam informações para entender que fatores permitem as árvores de Pandora serem mais altas que as da Terra.

\section{e) Teoria da Evolução das Espécies}

Avatar apresenta ao público um ambiente de condições extremas para os humanos, mas que seres locais vivem de forma eficiente e equilibrada nas circunstâncias que Pandora oferece, como ausência de oxigênio, atmosfera rica em dióxido de carbono e metano e uma gravidade menor que a terrestre.

A Terra é um planeta que deu certo para os humanos em vários sentidos. Sua abundância de água e de carbono, sua distância do sol, a presença de oxigênio e vasta diversidade de recursos naturais. Os cientistas achavam que não seria possível um ser sobreviver sem essas condições. Entretanto, há pouco tempo, cientistas encontraram vida existindo em ambientes extremos da Terra, como profundezas dos oceanos, em profundas camadas de gelo na Antártida e mesmo em locais de grande concentração de radiação (ROTHSCHILD; MANCINELLI, 2001).

Uma abordagem sobre que condições que um planeta precisaria ter para permitir a vida, poderiam ser algo bastante enriquecedor em uma aula de Ciências/Biologia. Seria a partir desses questionamentos, que o professor poderia utilizar essa abordagem em suas aulas, permitindo o aluno examinar a complexidade da vida e dos seres vivos, além de sua adaptabilidade para condições extremas. 
Nesse sentido, outra reflexão possível era problematizar como a seleção natural produziu seres tão bem-adaptados quanto aos organismos presentes na Terra? Desta forma, neste filme também se poderia observar aspectos da teoria da evolução proposta por Darwin e Wallace, na qual explicam como os seres vivos sofreram transformações ao longo tempo para se adaptar as mudanças que ocorreram no ambiente em que vivem (DARWIN, 2004). A teoria apresenta uma importante conexão dos seres vivos com o meio, assim como presente no filme Avatar, em que os seres estão adaptados a viverem nas condições peculiares dos ambientes naturais presentes em Pandora.

Desta forma, percebe-se que essa temática apresenta um número considerável de conceitos que podem ser usados e discutidos nas aulas de biologia, permitindo que o professor tenha uma boa ferramenta de trabalho para dinamizar a sua prática em sala de aula. Uma proposta de ensino para os professores de biologia seria um projeto sobre a adaptação dos seres vivos, no qual a turma poderia ser dividida em grupo e criar um ecossistema imaginário, em seguida cada equipe teria que criar animais adaptados para sobreviver nesse ambiente que cada equipe criou. Desta forma, o conceito de adaptação e sobrevivência poderia ser abordado de forma menos teórica e mais prática.

\section{f) Aspectos culturais}

Jake-Avatar e a princesa Neytiri estão caçando e ele mata um hexapede (Sexcruscervus caeruleus) com uma flecha. Jake toca o animal e faz uma oração proferindo as seguintes palavras: "Eu vejo você, meu irmão, e agradeço, sua alma irá retornar para Eywa, mas seu corpo permanecerá aqui, para servir de alimento para o povo" (AVATAR, 2009). Percebe-se nessa passagem um forte valor cultural do povo Na'vi, que Jake precisou incorporar para fazer parte da tribo. Há uma valorização dos Na'vi com a natureza, animais e outros seres de Pandora, além da lealdade e respeito com o lugar em que vivem.

Avatar possui um forte referencial cultural. Um dos conflitos recorrentes em Avatar é o colonialismo agressivo dos humanos, que esgotou todos os recursos naturais da Terra e os fizeram sair em busca de recursos em outros lugares do universo. Este enfoque é bastante rico em aulas que abordem o conceito de cultura e sociedade. Segundo Santos (2006) a cultura de um povo ou nação se refere a tudo aquilo que se caracteriza como existência social, como festas, cerimônias tradicionais, lendas, crenças, modo de vestir, suas comidas típicas, seu idioma entre outros. Nesse sentido, os Na'vi são seres culturais, criaturas sociais, linguísticas, trabalhadoras, tem conhecimento de valores, crenças, felicidade, sofrimento, são desse modo, seres culturais e históricos.

\section{g) Questões éticas}

Avatar traz uma mensagem claramente ecológica e anti-militarista, que exacerba a ideia de um mundo natural que não necessitaria de máquinas. O filme ressalta o lado inteligente da arquitetura orgânica da natureza, que se recria a todo instante diante do potencial destruidor das máquinas de exploração mineral. É possível se encantar pela natureza de Pandora em uma era onde nossa biodiversidade está sendo destruída.

Em uma das cenas o Coronel Milles Quadritch, chefe de segurança do programa de exploração de Unobtanium, dá a boas vindas aos recém-chegados em Pandora com uma descrição assustadora do local, com animais e plantas perigosas e principalmente os nativos, 
que, segundo ele, não querem outra coisa senão matar humanos.Outro ponto que se chama atenção no filme é o fato da cientista Dra. Grace Augustine, chefe do programa Avatar, mesmo cheia de boas intenções, serve a propósitos expansionistas, gananciosos e materialistas. O que se espera de um bom cientista, assim como de um bom soldado é cumprir seu dever, sem questionar a que propósito está servindo. Embora ela tenha sido honesta em sua atuação profissional, as vezes até corajosa, a Dra. Grace permanece por muito tempo, ignorando o verdadeiro rumo que sua pesquisa tomará. A partir dessas cenas é possível refletir junto aos alunos sobre a não-neutralidade da ciência e tecnologia.

Outro ponto de vista que merece destaque e que seria de grande discussão em atividade de ensino aprendizagem, estaria na relação entre os $\mathrm{Na}^{\prime} v i$ com os animais, apresentada no filme como impecável em termos éticos. Porém, em diversas passagens do filme, prevalece uma relação de domínio entre os animais (seres dominados) e os humanoides (seres dominantes), no qual, os animais seriam usado para satisfazer a vontade dos Na'vi e deveriam estar disponíveis sempre que precisassem.

O professor pode usar o conceito de Avatar para a abordagem de vários conteúdos da genética, como a ideia de genes, manipulação genética, hibridismo, transgênicos e o genoma humano. Os avatares só existem graças a uma pesquisa de engenharia genética avançada, que foi capaz de misturar o DNA humano com o de uma Na'vi, por tanto o avatar pode ser considerado o mais avançado Organismo Geneticamente Modificado (OMG) do século XXIII. Dito isso, se poderia trabalhar com os alunos sobre o que são os OMGs, qual foi o primeiro OMG criado? Qual a aplicação atual dos OMGs na Terra. Por ser um tema bastante polêmico, provoca ótimas discussões em aulas de Biologia, o planejamento dessa temática pode tornar a aula mais interessante e capaz de contribuir para a alfabetização científica dos alunos, visto que, tratam-se de conceitos que podem fazer parte da vida dos sujeitos.

O professor poder iniciar atividades com esse enfoque com os seguintes questionamentos: $O$ que leva uma tecnologia a se desenvolver antes de outra? A tecnologia estaria deixando de agregar valor às relações humanas? Em que sentido as tecnologias ajudam na convivência harmônica e digna entre os seres humanos? Usar exemplos práticos como a evolução dos celulares ou das TVs, ou ainda da internet pode contribuir de forma satisfatória para a prática de ensino.

\section{h) Aspectos religiosos}

Quando Selfridge e Quaritch se preparam para usar força letal contra o clã Omaticaya e sua floresta, a Dra. Grace Augustine protesta, tentando explicar que os nativos protegerão a todo custo seu território e Eywa estará com eles. Eywa é fundamental para o povo Na'vi e para Pandora. Em umas das cenas Jake percebe que os nativos veem o mundo como uma rede de energia que foi emprestada e deve ser devolvida. Eywa está no centro dessa rede, ela protege o equilíbrio da vida. Nesse sentido, talvez ela seja semelhante à Gaia (LOVELOCK, 2000). Nesse sentido, outro ponto que pode gerar uma discussão em aulas (não só nas de biologia) seria sobre a religiosidade tratada no filme. Temos a figura de Eywa que para os Na'vi é a deusa-mãe, e de certo modo, o paraíso. Ela acolherá todos os que morrerem.

Em outra cena Dra. Grace Augustine está morrendo, então tentam transferir sua alma, ou seja, sua essência para seu corpo Avatar. Mas a tentativa falha e Grace se junta Eywa. Parte da essência dos Na'vi mortos está viva dentro de Eywa e os vivos podem comunicar 
com eles através da árvore das almas. Todavia, por mais inteligente que a ideia seja, de onde veio Eywa? Como evoluiu? Será que essa religiosidade pode ser comparada a alguma presente pela espécie humana? São questões que podem contribuir para a problematização de questões CTSA e um ensino investigativo (CARVALHO, 2013).

Além disso, em um dos trechos Jake comenta que ele e Norm foram mandados para Pandora com o objetivo de controlar remotamente os corpos geneticamente modificados conhecidos como Avatar. Os Avatares se parecem com os $\mathrm{Na}^{\prime} v i$ (povo que habita Pandora), porém eles não são nem Na'vi nem humanos. São corpos híbridos, cultivados em tanques a partir de uma mistura do DNA humano e Na'vi. Os Avatares não têm mente própria e precisam ter a consciência de um condutor para funcionar. O condutor Jake Sully está ligado ao seu Avatar por uma conexão semelhante à telecinese. A princípio, os Avatares foram criados pela RDA para servirem de força de trabalho em Pandora, mas era muito caro produzi-los em larga escala. Depois os Avatares foram usados como conciliadores de conflitos entre os nativos e os humanos, também não obtiveram êxito. Desta forma, o Avatar foi direcionado para atividades de reconhecimento, ciência de campo e exploração, e secretamente, com as ordens do Coronel Miles Quaritch, para obter informações sobre os Na'vi.

\section{Considerações finais}

Percebe-se o quanto o trabalho com o filme de ficção Avatar pode contribuir para o desenvolvimento de um currículo CTSA voltado para a alfabetização científica dos sujeitos. Além disso, o apelo visual do filme associado ao enredo envolvente pode contribuir para despertar nos alunos o interesse pela ciência.

A etnografia de tela do filme identificou um alto potencial didático, não só na área da biologia, mas também na sociologia, filosofia, ensino religioso, geografia, física e química. Os apontamentos feitos no trabalho demonstraram que o filme pode ajudar no desenvolvimento de um trabalho em sala de sala feito pelos professores de diferentes áreas do conhecimento e ou conteúdos, e /ou em projetos interdisciplinares.

A partir de uma abordagem CTSA é possível favorecer a problematização dos conceitos e das cenas, explicação de fenômenos, aquisição de princípios científicos, promoção do senso crítico e interpretação dos acontecimentos do mundo, dentre outros. Desta forma, seu uso pode potencializar a aprendizagem dos alunos com um enfoque na alfabetização científica. Como sugestão para futuras investigações é possível apontar a necessidade de avaliação dos limites e possibilidades didáticas do filme para a construção de currículo CTSA centrados na alfabetização científica dos sujeitos em contextos reais de ensino e aprendizagem. 


\section{Referências}

AULER, D. Alfabetização científico-tecnológica: um novo "paradigma"? Ensaio: Pesquisa em Educação em Ciências, v. 5, n. 1, p. 68-83, 2003.

BALESTRIN, P.; SOARES, R. "Etnografia de tela": uma proposta metodológica. In: MEYER, D. E.; PARAÍsO, M. A. (Eds.). Metodologia de Pesquisas Pós-críticas em Educação. 2. ed. Belo Horizonte: Mazza Edições, 2012. p. 89-112.

BAXTER, S. A ciência de Avatar: a verdade e a ficção por trás das tecnologias do filme de maior bilheteria de todos os tempos. 1. ed. São Paulo: Cultrix, 2013.

BIZZO, N. Ciência: fácil ou difícil? 2. ed. [s.I.] Ática, 2002.

CAJAS, F. Alfabetización científica y tecnológica: la transposición didáctica del conocimiento tecnológico. Enseñanza de las Ciencias, v. 19, n. 2, p. 243-254, 2001.

CARAMellO, G. W. et al. Articulação Centro de Pesquisa: Escola Básica: contribuições para a alfabetização científica e tecnológica. Revista Brasileira de Ensino de Física, v. 32, n. 3, p. 19, 2010.

CARVALHO, A. M. Ensino de Ciências por Investigação: condições para implementação em sala de aula. In: CARVALHO, A. M. (org.). Ensino de ciências por investigação: condições para implementação em sala de aula. São Paulo: Cengage Learning, 2013. p. 1-20.

CHASSOT, A. Alfabetização científica: uma possibilidade para a inclusão social. Revista Brasileira de Educação, n. 22, p. 157-158, 2003.

DARWIN, C. A Origem das espécies. 2. ed. São Paulo: Martin Claret, 2004.

DEMO, P. Conhecimento Moderno: sobre ética e intervenção do conhecimento. Petrópolis: Vozes, 2002.

EGGENSPERGER, K. Avatar e os estudos culturais: algumas observações. Revista X, v. 2, p. 90-103, 2009.

FAVILA, M. A.; ADAIME, M. Uma análise da contextualização na perspectiva CTSA sob a ótica do professor de Química. Revista do Centro do Ciências Naturais e Exatas - UFSM, Santa Maria, v. 13, no 13, out.-dez, p. 2865 - 2873, 2013.

HOYLE, F.; WICKRAMASINGHE, C. Astronomical Origins of Life: Steps Towards Panspermia," Kluwer Academic Press, 2000.

LACERDA, G. Alfabetização científica e formação profissional. Educação \& Sociedade, v. 60, p. 91-108, 1997.

LOVELOCK, J. Gaia: a new look at life on earth. [s.I.] Oxford University Press, 2000.

MACHADO, V. R.; SASSERON, L. H. As perguntas em aulas investigativas de Ciências: a construção teórica de categorias. Revista Brasileira de Pesquisa em Educação em Ciências, v. 12, n. 2, p. 29-44, 2012.

MAIA, F. N. A ciência por dentro. 6. ed. Petrópolis: Vozes, 2000.

MORAN, J. M. Ensino e aprendizagem inovadores com tecnologias. Informática na educação: teoria \& prática, v. 3, n. 1, p. 137-144.9, 2008. 
RESENDE, C. H. S. O uso de filmes como material pedagógico: Avatar, no estudo da natureza, da ciência e tecnologia. Universidade Federal de Minas Gerais, 2010.

RIAL, C. S. Por uma antropologia do visual contemporâneo. Horizontes Antropológicos, v. 1, n. 2, p. 119-128, 1995.

RINK, A. Avatar: metáforas de resignificação e (re)imaginação criativa do mundo. Revista de Estudos em Linguagem e Tecnologia, n. 2, p. 113-121, 2010.

RODRIGUES, F.; et al. Astrobiologia: estudando a vida no universo. In: GALANTE, D. et al. (Orgs.) Astrobiologia: uma ciência emergente. Núcleo de Pesquisa em Astrobiologia. São Paulo: Tikinet Edição: IAG/USP, 2016

ROTHSCHILD, L.; MANCINELLI, R. Life in extreme environments. Nature, v. 409, p. 1092-1100, 2001.

SANTOS, J. L. O que é Cultura. São Paulo: Brasiliense, 2006.

SASSERON, L. H. Alfabetização científica, ensino por investigação e argumentação: relações entre ciências da natureza e escola. Ensaio Pesquisa em Educação em Ciências, v. 17, p. 4967, 2015.

SASSERON, L. H.; CARVALHO, A. M. Alfabetização científica: uma revisão bibliográfica. Investigações em Ensino de Ciências, v. 16, n. 1, p. 59-77, 2011 b.

SASSERON, L. H.; CARVALHO, A. M. Construindo argumentação na sala de aula: a presença do ciclo argumentativo, os indicadores de alfabetização científica e o padrão de Toulmin. Ciência e Educação, Bauru, v. 17, n. 1, p. 97-114, 2011 a.

SILVA, B. N. Cinema e a sala de aula: um caminho para a formação. Revista Espaço Acadêmico, n. 93, p. 1-5, 2009.

SILVA, L. R.; SILVA, R. S. Gestão Escolar e Tecnologias. Manaus: UEA Edições, 2008.

SILVA, Penha Souza; MORTIMER, Eduardo Fleury. O projeto água em foco como uma proposta de formação no PIBID. Química Nova na escola, v. 34, n. 4, p. 240-247, 2012.

WALKER, M. M.; GREEN, C. R. Structure, function, and use of the magnetic sense in animal. Journal of Applied Physics, v. 5, n. 5, p. 1- 10, 2000.

WAPNER, P. Environmental Activism and World Civic Politics. New York: State University of New York Press, 1996. 